\title{
PARÂMETROS DE DEGRADABILIDADE POTENCIAL DOS COMPONENTES DA PAREDE CELULAR DAS SILAGENS DE SEIS GENÓTIPOS DE SORGO (Sorghum bicolor (L.) Moench), NA PRESENÇA OU AUSÊNCIA DE TANINO NO GRÃO, AVALIADOS PELA TÉCNICA "IN SITU"
}

\author{
LÍVIO RIBEIRO MOLINA ${ }^{1}$ \\ NORBERTO MARIO RODRIGUEZ ${ }^{1}$ \\ LÚCIO CARLOS GONÇALVES ${ }^{1}$ \\ IRAN BORGES ${ }^{1}$ \\ BRENO MOURÃO DE SOUSA ${ }^{2}$
}

\begin{abstract}
RESUMO - Para testar o efeito da presença de tanino no grão sobre os parâmetros de degradabilidade potencial dos componentes da parede celular de seis genótipos de sorgo para silagem, conduziu-se este experimento utilizando a técnica da degradabilidade "in situ". Quatro novilhos mestiços, canulados no rúmen, foram utilizados. Os novilhos foram alimentados "ad libitum" duas vezes ao dia, individualmente, com feno de Tifton 85. Foram incubadas silagens de sorgo no estádio de grão leitoso, pertencentes a seis genótipos: BR 303, BR 304, BR 601e AG 2006 (sem tanino no grão); BR 700 e
\end{abstract}

BR 701 (com tanino). Foram incubadas $5 \mathrm{~g}$ de amostra dentro de bolsas de náilon suspensas no rúmen, nos tempos: $6,12,24,48,72$ e 96 horas. O tempo zero $\left(\mathrm{t}_{0}\right)$ foi utilizado para cálculo da fração solúvel. A presença do tanino reduziu a extensão de degradação da fibra em detergente neutro (FDN) e da fibra em detergente ácido (FDA) nas silagens de sorgo BR 700 e BR 701. A degradabilidade potencial da FDN e da FDA foi reduzida pela presença do tanino. Não foi observado efeito depressivo do tanino sobre as taxas de degradação para nenhum nutriente, em nenhuma silagem testada.

TERMOS PARA INDEXAÇÃO: Bovino, parede celular, rúmen, sorgo, tanino.

\section{POTENTIAL DEGRADABILITY PARAMETERS OF THE CELL WALL COMPOUNDS OF SIX SORGHUM SILAGE GENOTYPES (Sorghum bicolor (L.) Moench), WITH OR WITHOUT TANNIN ON GRAIN, EVALUATED BY "IN SITU" TECHNIQUE}

\begin{abstract}
The aim of these experiment was to evaluate the effect of tannin on grain over potential degradability parameters of the cell wall compounds of six sorghum silage genotypes by "in situ" technique. Four crossbred steers, canulated in rumen, were used. The steers were fed "ad libitum" twice at day with a diet comprised by Tifton 85 (Cynodon dactylon) hay. Six sorghum silage genotypes, harvested at milk stage, were incubated in the rumen: BR 303, BR 304, BR 601, and AG 2006 (without tannin on grain); BR 700, and BR 701 (with tannin on
\end{abstract}

grain). Five grams of samples were incubated into nylon bags, and suspended in the rumen by times: $6,12,24,48$, 72 , and 96 hours. The time zero $\left(\mathrm{t}_{0}\right)$ was used to calculate the soluble fraction. Tannin decrease the extent of degradation of neutral detergent fiber (NDF), and acid detergent fiber (ADF) of BR 700 and BR 701 sorghum silages. The potential degradability of the NDF and ADF was reduced by tannin presence on grain. There was not effect of tannin on degradation rate of the cell wall compounds in anyone sorghum silage genotypes tested.

INDEX TERMS: Cattle, cell wall, rumen, sorghum, tannin.

1. Professor, Dr., Departamento de Zootecnia da Escola de Veterinária da UFMG, Caixa Postal 567 - 30123-970 Belo Horizonte, MG.

2. Médico Veterinário, Mestre em Produção Animal/UFMG, estudante de Doutorado em Ciência Animal/UFMG, Bolsista CNPq. Rua Nunes Vieira, 358/702, Santo Antônio - 30350-120 - Belo Horizonte, MG - TEL: (0XX31) 3344-4830 ou brenoms@hotmail.com. 


\section{INTRODUÇÃO}

Embora as regiões de clima tropical apresentem grande potencial de produção de forragens, elas estão sujeitas a variações climáticas que influenciam essa produção. Os problemas decorrentes da estacionalidade de produção podem ser minimizados pelo armazenamento do alimento na forma de silagem (PIZARRO, 1978).

A cultura de sorgo para ensilagem vem crescendo e representa grande percentual da área cultivada para silagem no Brasil (10 a 12\%). Além do valor nutritivo próximo ao da silagem de milho (aproximadamente 95\%), outra vantagem dessa silagem sobre a de milho é que a planta conserva vivo o seu sistema radicular, o que possibilita, havendo condições de umidade, temperatura e fertilidade do solo, rebrota, que poderá produzir até $60 \%$ da produção de matéria seca do primeiro corte (ZAGO, 1991).

Entretanto, Demarchi et al. (1995) mencionaram baixo desempenho produtivo em animais alimentados com a silagem de sorgo em comparação com a silagem de milho. Essa observação, segundo os autores, poderia estar relacionada à presença de tanino no grão. Taninos seriam substâncias polifenólicas (polímeros de fenóis) solúveis em água, com grande quantidade de grupos hidroxifenólicos e, em alguns casos, com grupos carboxílicos, que os capacitariam de formar ligações cruzadas e precipitar proteínas e outras moléculas (amido, celulose, hemicelulose e pectina) em solução aquosa, formando complexos estáveis (HAGERMAN e BUTLER, 1989; JANSMAN, 1993; REED, 1995; DAWSON et al., 1999).

Portanto, torna-se imperativo a avaliação da digestibilidade de uma forrageira e de seus diversos componentes nutricionais. Para isso, idealizaram-se os estudos "in situ" com bolsas de náilon, capaz de fornecer parâmetros da cinética da digestão, relacionados à degradabilidade ruminal dos nutrientes, difíceis de serem obtidos em estudos in vitro. Esses parâmetros são de fundamental importância na avaliação nutricional de alimentos para ruminantes (NOCEK, 1988).

Objetivou-se com este trabalho avaliar o efeito do tanino na degradabilidade "in situ" dos componentes da parede celular da célula vegetal (fibra em detergente neutro e fibra em detergente ácido) de silagens de seis genótipos de sorgo, ensilados no estádio de grão leitoso.

\section{MATERIAL E MÉTODOS}

O experimento foi conduzido nos estábulos do Hospital Veterinário da Escola de Veterinária da UFMG, no município de Belo Horizonte (MG). Foram utilizados quatro bovinos machos, mestiços HolandêsZebu, com peso aproximado de $350 \mathrm{~kg}$. Os animais foram canulados no rúmen e alojados em baias individuais, onde eram alimentados duas vezes ao dia com uma dieta composta por feno de Tifton 85, ad libitum.

Foram utilizadas silagens de sorgo provenientes de seis genótipos colhidos no estádio de grão leitoso: BR 303, BR 304, BR 601 e AG 2006 (sem tanino no grão) e BR 700 e BR 701 (com tanino no grão). A composição química (\% MS) das silagens utilizadas para incubação ruminal encontra-se na Tabela 1.

As amostras experimentais foram moídas em peneira de $5 \mathrm{~mm}$ e $5 \mathrm{~g}$ foram adicionadas em bolsas de náilon. Essas foram presas a uma corda de $60 \mathrm{~cm}$ de comprimento, sendo uma das extremidades presa a uma âncora metálica de $300 \mathrm{~g}$ de peso, ao passo que a outra foi fixada à parte externa da cânula ruminal. Cada animal continha os tratamentos sob o mesmo tempo de incubação, de modo que todas as bolsas fossem retiradas de uma só vez. Utilizaram-se quatro réplicas de cada genótipo por animal, no mesmo horário. Para determinação da fração solúvel no tempo zero $\left(\mathrm{t}_{0}\right)$, três novas repetições foram feitas para cada genótipo e lavadas manualmente em água corrente por 20 minutos.

Os tempos de incubação foram: $6,12,24,48,72$ e 96 horas. Após o período de incubação, as bolsas foram imersas em água fria e lavadas manualmente em água corrente, até que essa se mostrasse límpida. Após secagem a $65^{\circ} \mathrm{C}$ em estufa por 48 horas, as amostras foram pesadas, sendo registrado o peso do resíduo de incubação. Esse resíduo foi moído em peneira de $1 \mathrm{~mm}$ para posteriores análises químicas.

As análises químicas foram feitas no Laboratório de Nutrição Animal do Departamento de Zootecnia da Escola de Veterinária da UFMG. As silagens de sorgo e os resíduos de incubação foram analisados quanto aos componentes da parede celular, pelo método seqüencial de Soest et al. (1991).

As equações de regressão para o desaparecimento da FDN e da FDA foram estimadas usando o software SAEG, versão 7.0. Para o cálculo da degradabilidade potencial das silagens de sorgo, foi utilizado o modelo proposto por Sampaio (1988) a partir de uma simplificação do modelo exponencial de Ørskov e McDonald (1979): P=A + $\mathrm{B} * \mathrm{e}^{-\mathrm{Ct}}$, em que $\mathrm{P}=$ porcentagem real do nutriente degradado após t horas de incubação no rúmen; $\mathrm{A}=$ porcentagem máxima de degradação do material na bolsa (assíntota); B = fração potencialmente degradável do material que permanece na bolsa após o tempo zero; $\mathrm{C}=$ taxa de degradação da fração que permanece na bolsa após o tempo zero. 
TABELA 1 - Composição química (\% da matéria seca) e valor de pH das silagens de sorgo sem tanino (BR 303, BR 304, BR 601 e AG 2006) e com tanino no grão (BR 700 e BR 701), antes da incubação ruminal.

\begin{tabular}{lcccccc}
\hline \multirow{2}{*}{$\begin{array}{c}\text { Parâmetros } \\
\text { Nutricionais }\end{array}$} & \multicolumn{7}{c}{ Silagens de sorgo } \\
\cline { 2 - 7 } & BR 303 & BR 304 & BR 601 & AG 2006 & BR 700 & BR 701 \\
\hline MS & 28,95 & 32,05 & 20,80 & 27,35 & 27,56 & 26,79 \\
PB & 7,57 & 8,45 & 5,57 & 6,66 & 6,36 & 6,01 \\
FDN & 41,93 & 38,65 & 54,51 & 50,42 & 51,85 & 52,91 \\
FDA & 25,03 & 22,57 & 33,21 & 30,92 & 33,02 & 32,87 \\
Celulose & 19,85 & 17,95 & 27,15 & 18,45 & 22,73 & 26,51 \\
Hemicelulose & 16,89 & 16,08 & 21,31 & 19,51 & 18,83 & 20,03 \\
Lignina & 4,21 & 3,33 & 4,49 & 6,73 & 3,65 & 5,03 \\
pH & 3,8 & 3,6 & 3,8 & 3,8 & 3,8 & 3,8 \\
N-NH /NT $^{\text {Tanino no grão }}{ }^{*}$ & 8,16 & 8,75 & 11,08 & 10,49 & 10,38 & 11,21 \\
\hline
\end{tabular}

MS = matéria seca, $\mathrm{PB}$ = proteína bruta, FDN = fibra em detergente neutro, FDA = fibra em detergente ácido, $\mathrm{N}-\mathrm{NH}_{3} / \mathrm{NT}=$ nitrogênio amoniacal em relação ao nitrogênio total.

(*) dado obtido da EMBRAPA Milho e Sorgo - Sete Lagoas/MG.

O delineamento experimental utilizado foi o de blocos inteiramente ao acaso, em esquema de parcelas sub-subdivididas, sendo as parcelas as seis silagens de sorgo, e as subparcelas, os seis tempos de incubação. As médias para o desaparecimento da FDN e da FDA entre as silagens de sorgo foram comparadas a $5 \%$ de probabilidade, utilizando-se o teste de Student-NewmanKeuls (SNK). As médias foram ajustadas ao modelo:

$$
\mathrm{Y}_{\mathrm{ijkl}}=\mu+\mathrm{B}_{\mathrm{i}}+\mathrm{P}_{\mathrm{j}}+\mathrm{S}_{\mathrm{k}}+\mathrm{I}_{(\mathrm{jk}) 1}+\mathrm{e}_{\mathrm{ijk} \mathrm{k}} \text {, em que: }
$$

$\mathrm{Y}_{\mathrm{ikjl}}=$ variável dependente (desaparecimento da FDN e da FDA no tempo t); $\mu$ = média geral (intercepto); $\mathrm{B}_{\mathrm{i}}=$ efeito do bloco $\mathrm{i}$ (bovino : $\left.\mathrm{i}=1, \ldots, 4\right) ; \mathrm{P}_{\mathrm{j}}=$ efeito da parcela $\mathrm{j}$ (silagem de sorgo: $\mathrm{j}=\mathrm{BR} 303, \ldots$, BR 701); $S_{k}=$ efeito da sub-parcela $k$ (tempo de incubação: $\mathrm{k}=6, \ldots, 96$ horas $) ; \mathrm{I}_{(\mathrm{jk}) 1}=$ interação 1 entre as silagens de sorgo $\mathrm{j}$ e o tempo de incubação $\mathrm{k}$; $\mathrm{e}_{\mathrm{ijk}}$ $=$ erro geral da média.

\section{RESULTADOS E DISCUSSÃO}

A incubação de amostras vegetais em bolsas suspensas no rúmen por até $96 \mathrm{~h}$ mostrou-se suficiente em atingir os valores máximos (assíntota) de desapare- cimento da FDN, uma vez que não houve diferença $(\mathrm{P}>0,05)$ entre as médias de desaparecimento com 72 ou 96 horas de incubação nas silagens de sorgo testadas, exceto para a silagem do BR 304 (Tabela 2).

Exceto nos tempos de incubação de 6, 24 e 96 horas, todas as silagens de sorgo testadas não diferiram ( $p>0,05)$ quanto ao desaparecimento médio da FDN (Tabela 2). Às 96 horas, as silagens de sorgo BR 700 $(60,47 \%)$ e BR $701(58,80 \%)$ não diferiram entre si $(\mathrm{p}>0,05)$, sendo semelhantes às silagens do BR 303 $(67,47 \%)$ e AG $2006(66,03 \%)$ e menores $(\mathrm{p}<0,05)$ que a do BR 304 (71,11\%) e do BR 601 (72,10\%). Portanto, nas silagens de sorgo dos genótipos BR 700 e BR 701, a presença de tanino no grão influenciou a média de desaparecimento da FDN, reduzindo-a.

Magalhães et al. (1997) citaram que concentrações de tanino (proantocianidinas ou taninos condensados) inferiores a $0,70 \%$ no grão de sorgo não seriam prejudiciais à dieta alimentar dos animais, ao passo que Rodrigues et al. (1998) citaram ser esse valor cerca de 0,80\%. Rittner e Reed (1992) verificaram que os fenóis solúveis e as proantocianidinas solúveis tiveram efeitos negativos sobre a digestibilidade da FDN. A presença 
de tanino na dieta também reduziu a digestibilidade aparentes da MS, do nitrogênio e da FDN em ovelhas (DAWSON et al., 1999). De acordo com Reed (1995), o efeito depressivo dos taninos sobre a digestibilidade da parede celular da célula vegetal pode ser explicado pelas ligações desse polifenol com enzimas bacterianas e/ou pela formação de complexos insolúveis com carboidratos da parede celular.

Os resultados das médias de desaparecimento da FDN ajustaram ao modelo exponencial proposto por Ørskov e McDonald (1979), adaptado por Sampaio (1988). As equações de degradabilidade potencial da FDN, para cada silagem, foram: $\mathrm{BR} 303$ : $\mathrm{P}=75,00+$ $59,88 * \mathrm{e}^{-0,0204 \mathrm{t}}, \mathrm{R}==0,918 ; \quad \mathrm{BR}$ 304: $\mathrm{P}=75,00+$ $52,82 * \mathrm{e}^{-0,0183 \mathrm{t}}, \mathrm{R}^{2}=0,814 ;$ BR 601: $\mathrm{P}=75,00+50,34 * \mathrm{e}$ $0,0248 \mathrm{t}, \mathrm{R}^{2}=0,856$; BR 700: $\mathrm{P}=41,02+107,56 * \mathrm{e}^{-0,0184 \mathrm{t}}$, $\mathrm{R}^{2}=0,767 ; \quad \mathrm{BR} 701: \mathrm{P}=66,67+45,38 * \mathrm{e}^{-0,0243 \mathrm{t}}$, $\mathrm{R}^{2}=0,830 ;$ AG 2006: $\mathrm{P}=75,00+53,27 * \mathrm{e}^{-0,0249 \mathrm{t}}$, $\mathrm{R}^{2}=0,865$.

As degradabilidades potenciais encontradas neste experimento foram: 75,00\% (BR 303, BR 304, BR 601, AG 2006), 66,67\% (BR 701) e 41,02\% (BR 700). Serafim (1998) encontrou resultados superiores ao desse experimento para as silagens de sorgo dos híbridos BR 303 (91,19\%), BR 601 (85,31\%) e BR 700 $(82,54 \%)$. Por outro lado, Lara (1999) observou, para o híbrido de sorgo BR 601, ensilado aos 7, 28 e 49 dias de florescimento, $70,00 \%$ inferiores ao observado para as silagens de BR 303, BR 304, BR 601 e AG 2006, mas superiores às de $\mathrm{BR} 700 \mathrm{e} \mathrm{BR} 701$.

Semelhante ao observado para a média de desaparecimento da FDN às 96 horas, a presença de tanino no grão das silagens de sorgo dos genótipos BR 700 e BR 701 exerceu um efeito inibitório sobre o potencial de degradação da FDN, confirmando a capacidade de interação entre o polifenol e os componentes da parede celular, descritos anteriormente.

As taxas de degradação da FDN das silagens incubadas no rúmen foram: $2,49 \% / \mathrm{h}$ (AG 2006), 2,48 $\% / \mathrm{h}$ (BR 601), 2,43\%/h (BR 701), 2,04 \%/h (BR 303), $1,84 \% / \mathrm{h}$ (BR 700) e $1,83 \% / \mathrm{h}$ (BR 304). Serafim (1998) observou, para a silagem de sorgo dos híbridos BR 303, BR 601 e BR 700, taxas de degradação de 1,00 $\% / h$, ao passo que Lara (1999), para a silagem do BR 601 colhido para ensilagem aos 7, 28 e 49 dias após o florescimento, 2,43, 1,76 e 1,47\%/h, respectivamente.

Não houve diferenças entre os genótipos de sorgo ensilados quanto ao desaparecimento médio da FDA em nenhum dos tempos estudados (Tabela 3), exceto para 96 horas, em que a silagem de sorgo do BR 701 $(57,17 \%)$ apresentou resultados menores $(\mathrm{p}<0,05)$ que do BR 303 (69,98\%), BR 304 (72,85\%) e BR 601 $(72,66 \%)$, sendo, no entanto, semelhante $(p>0,05)$ ao BR 700 (64,08\%) e AG 2006 (66,02\%).

TABELA 2 - Desaparecimento médio da fibra em detergente neutro (\% da FDN) dos genótipos de sorgo para silagem no tempo zero $\left(\mathrm{t}_{0}\right)$ e nos tempos de incubação ruminal (horas).

\begin{tabular}{ccccccc}
\hline \multirow{2}{*}{$\begin{array}{c}\text { Tempo de incubação } \\
\text { (horas) }\end{array}$} & \multicolumn{7}{c}{ Silagens de sorgo } \\
\cline { 2 - 7 } & BR 303 & BR 304 & BR 601 & AG 2006 & BR 700 & BR 701 \\
\hline$t_{0}$ & 21,04 & 21,82 & 23,01 & 17,93 & 19,35 & 22,47 \\
6 & $22,92 \mathrm{Dab}$ & $27,28 \mathrm{Dab}$ & $32,53 \mathrm{Da}$ & $19,32 \mathrm{Db}$ & $27,62 \mathrm{Cab}$ & $23,15 \mathrm{Cab}$ \\
12 & $30,39 \mathrm{CDa}$ & $39,92 \mathrm{Ca}$ & $33,28 \mathrm{Da}$ & $24,89 \mathrm{Da}$ & $27,84 \mathrm{Ca}$ & $25,55 \mathrm{Ca}$ \\
24 & $37,22 \mathrm{Cab}$ & $39,62 \mathrm{Cab}$ & $46,83 \mathrm{Ca}$ & $36,28 \mathrm{Cab}$ & $33,90 \mathrm{Cb}$ & $37,34 \mathrm{Bab}$ \\
48 & $53,29 \mathrm{Ba}$ & $55,05 \mathrm{Ba}$ & $55,72 \mathrm{Ba}$ & $52,13 \mathrm{Ba}$ & $50,27 \mathrm{Ba}$ & $48,99 \mathrm{Aa}$ \\
72 & $62,19 \mathrm{Aa}$ & $56,74 \mathrm{Ba}$ & $68,31 \mathrm{Aa}$ & $62,47 \mathrm{Aa}$ & $59,55 \mathrm{Aa}$ & $56,29 \mathrm{Aa}$ \\
96 & $67,47 \mathrm{Aab}$ & $71,11 \mathrm{Aa}$ & $72,10 \mathrm{Aa}$ & $66,03 \mathrm{Aab}$ & $60,47 \mathrm{Ab}$ & $58,80 \mathrm{Ab}$ \\
\hline
\end{tabular}

1 - médias seguidas pela mesma letra maiúscula não diferem $(p>0,05)$ para a mesma coluna; 2 - médias seguidas pela mesma letra minúscula não diferem $(\mathbf{p}>0,05)$ para a mesma linha; Teste SNK; Coeficiente de variação: $14,41 \%$. 
TABELA 3 - Desaparecimento médio da fibra detergente ácido (\% da FDA) dos genótipos de sorgo para silagem no tempo zero $\left(\mathrm{t}_{0}\right)$ e nos tempos de incubação ruminal (horas).

\begin{tabular}{ccccccc}
\hline \multirow{2}{*}{$\begin{array}{c}\text { Tempo de incubação } \\
\text { (horas) }\end{array}$} & \multicolumn{7}{c}{ Silagens de sorgo } \\
\cline { 2 - 7 } & BR 303 & BR 304 & BR 601 & AG 2006 & BR 700 & BR 701 \\
\hline $\mathrm{t}_{0}$ & 9,4 & 9,48 & 5,65 & 4,19 & 10,32 & 5,64 \\
6 & $25,23 \mathrm{Da}$ & $32,85 \mathrm{Ca}$ & $34,67 \mathrm{Ca}$ & $20,71 \mathrm{Da}$ & $28,51 \mathrm{Ba}$ & $23,71 \mathrm{Ca}$ \\
12 & $33,69 \mathrm{CDa}$ & $39,39 \mathrm{Ca}$ & $35,64 \mathrm{Ca}$ & $26,03 \mathrm{Da}$ & $31,98 \mathrm{Ba}$ & $27,80 \mathrm{Ca}$ \\
24 & $39,72 \mathrm{Ca}$ & $42,05 \mathrm{Ca}$ & $48,77 \mathrm{Ba}$ & $38,49 \mathrm{Ca}$ & $36,05 \mathrm{Ba}$ & $40,33 \mathrm{Ba}$ \\
48 & $56,01 \mathrm{Ba}$ & $57,21 \mathrm{Ba}$ & $56,58 \mathrm{Ba}$ & $52,35 \mathrm{Ba}$ & $53,40 \mathrm{Aa}$ & $45,15 \mathrm{Ba}$ \\
72 & $64,57 \mathrm{ABa}$ & $58,66 \mathrm{Ba}$ & $69,55 \mathrm{Aa}$ & $64,28 \mathrm{Aa}$ & $62,11 \mathrm{Aa}$ & $55,19 \mathrm{Aa}$ \\
96 & $69,98 \mathrm{Aa}$ & $72,85 \mathrm{Aa}$ & $72,66 \mathrm{Aa}$ & $66,02 \mathrm{Aab}$ & $64,08 \mathrm{Aab}$ & $57,17 \mathrm{Ab}$ \\
\hline
\end{tabular}

1 - médias seguidas pela mesma letra maiúscula não diferem (p>0,05) para a mesma coluna; 2 - médias seguidas pela mesma letra minúscula não diferem $(\mathbf{p}>0,05)$ para a mesma linha; Teste SNK; Coeficiente de variação: $17,55 \%$.

A menor porcentagem de desaparecimento com 96 horas de incubação foi para a silagem de sorgo BR 701 (57,17\%), seguido do BR 700 (64,08\%) e AG 2006 $(66,02 \%)$. Os menores resultados foram observados nos dois materiais que apresentaram tanino no grão. Esses compostos polifenólicos apresentaram efeito inibitório na extensão de degradação da FDA no rúmen, quando da incubação de materiais em bolsas suspensas no rúmen.

O tanino tem sido considerado componente nutricional responsável por reduzir o valor nutricional da silagem de sorgo (SERAFIM, 1998; LARA, 1999). De acordo com Reed (1995), os taninos reduziriam a digestibilidade da parede celular da célula vegetal que, segundo Sousa (2001), seria justificada por: inibição de enzimas microbianas (interação tanino-proteína), inibição direta do crescimento microbiano e indisponibilização do substrato ao ataque microbiano, mediante a formação de complexos insolúveis.

Os resultados das médias de desaparecimento da FDA ajustaram ao modelo exponencial proposto por Ørskov e McDonald (1979), adaptado por Sampaio (1988). As equações de degradabilidade potencial da FDA, para cada silagem, foram: $B R$ 303: $P=70,00+$ $57,48 * \mathrm{e}^{-0,0260 \mathrm{t}}, \mathrm{R}^{2}=0,903$; BR 304: $\mathrm{P}=70,00+47,46 * \mathrm{e}^{-}$ $0,0222 \mathrm{t}, \mathrm{R}^{2}=0,775$; BR 601: $\mathrm{P}=70,00+46,45^{*} \mathrm{e}^{-0,0318 \mathrm{t}}$, $\mathrm{R}^{2}=0,842 ; \quad \mathrm{BR}$ 700: $\mathrm{P}=43,77+113,28 * \mathrm{e}^{-0,0185 \mathrm{t}}$, $\mathrm{R}^{2}=0,742 ; \quad$ BR 701: $\mathrm{P}=61,11+40,34 * \mathrm{e}^{-0,0291 \mathrm{t}}$,
$\mathrm{R}^{2}=0,628 ;$ AG 2006: $\mathrm{P}=70,00+50,70 * \mathrm{e}^{-0,0323 \mathrm{t}}$, $\mathrm{R}^{2}=0,796$.

A degradabilidade potencial das silagens de sorgo testadas foram: 70\% (BR 303, BR 304, BR 601, AG 2006), 61,11\% (BR 701) e 43,77\% (BR 700). Os menores valores foram para aquelas silagens nas quais o tanino se fez presente no grão (BR 700 e BR 701). O tanino parece ter inibido o potencial de degradação das silagens de sorgo testadas no presente experimento, o que confirma o efeito sobre os componentes da parede celular da célula vegetal.

De acordo com Sampaio (1988), taxas de degradação de 2 a $6 \% /$ h definiriam os alimentos volumosos como de boa qualidade. Segundo essa classificação, somente a silagem do sorgo BR $700(1,85 \% / \mathrm{h})$ não poderia ser assim classificada, já que material exibiu taxas de degradação inferiores a $2 \% / \mathrm{h}$.

\section{CONCLUSÕES}

A presença de tanino em genótipos de sorgo ensilados no estádio de grão leitoso reduziu a extensão de degradação (média de desaparecimento com 96 horas de incubação) e a degradabilidade potencial da fibra em detergente neutro e da fibra em detergente ácido nas silagens de sorgo BR 700 e BR 701.

A presença de tanino no grão não influencia as taxas de degradação $(\% / \mathrm{h})$ das amostras de silagens de 
sorgo incubadas no rúmen, para nenhum parâmetro nutricional testado.

\section{REFERÊNCIAS BIBLIOGRÁFICAS}

DAWSON, J. M.; BUTTERY, P. J.; JENKINS, D. Effects of dietary quebracho tannin on nutrient utilisation and tissue metabolism in sheep and rats. Journal of the Science and Food Agriculture, London, v. 79, n. 11, p. 1423-1430, 1999.

DEMARCHI, J. J. A. A.; BOIN, C.; BRAUN, G. A cultura do sorgo (Sorghum bicolor L. Moench) para a produção de silagens de alta qualidade. Zootecnia, Nova Odessa, v. 33, n. 3, p. 111-136, 1995.

HAGERMAN, A. E.; BUTLER, L. G. Choosing appropriate methods and standards for assaying tannin. Journal of Chemical Ecology, New York, v. 15, n. 6, p. $1795-1810,1989$.

JANSMAN, A. J. M. Tannins in feedstuffs for simplestomached animals. Nutrition Research Reviews, Cambridge, v. 6, p. 209-236, 1993.

LARA, A. C. Degradabilidade "in situ" dos componentes nutricionais das silagens do sorgo BR 601 colhidos em três estádios de maturação. 1999. 67 f. Dissertação (Mestrado em Zootecnia, Nutrição Animal) - Universidade Federal de Minas Geris, Escola de Veterinária, Belo Horizonte, 1999.

MAGALHÃES, P. C.; RODRIGUES, W. A.; DURÃES, F. O. M. Tanino no grão de sorgo: bases fisiológicas e métodos de determinação. Sete Lagoas: EMBRAPA-CNPMS, 1997. 26 p. (Circular Técnica, 27).

NOCEK, J. E. "In situ" and other methods to estimate ruminal protein and energy digestibility: a review. Journal of Dairy Science, Champaign, v. 71, n. 8, p. 2051-2069, 1988.

ØRSKOV, E. R.; MCDONALD, I. The estimation of protein degradability in the rumen from incubation measurements weighted according to rate of passage. Journal of Agriculture Science, Cambridge, v. 92, p. 499-503, 1979.
PIZARRO, E. A. Alguns fatores que afetam o valor nutritivo da silagem de sorgo. Informe Agropecuário, Belo Horizonte, v. 4, n. 47, p. 12-19, 1978.

REED, J. D. Nutritional toxicology of tannins and related polyphenols in forage legumes. Journal of Animal Science, Champaign, v. 73, n. 5, p. 15161528, 1995.

RITTNER, U.; REED, J. D. Phenolics and in-vitro degradability of protein and fibre in west African browse. Journal of the Science and Food Agriculture, London, v. 58, n. 1, p. 21-28, 1992.

RODRIGUES, W. A.; MAGALHÃES, P. C.; SANTOS, F. G. Métodos para determinar taninos em sorgo, avaliando-se o desempenho de aves e a digestibilidade in vitro da matéria seca. Ciência e Agrotecnologia, Lavras, v. 22, n. 4, p. 540-550, 1998.

SAMPAIO, I. B. M. Experimental designs and modeling techniques in the study of roughage degradation in rumen and growth of ruminants. 1988. $214 \mathrm{f}$. Thesis (Doctor in Fisiology) - University of Reading, Reading, 1988.

SERAFIM, M. V. Degradabilidade "in situ" dos componentes nutricionais das silagens de três cultivares de sorgo (BR 303, BR 601 e BR 700). 1998. 87 f. Dissertação (Mestrado em Zootecnia, Nutrição Animal) - Escola de Veterinária, Belo Horizonte, 1998.

SOEST, P. J. van; ROBERTSON, J. B.; LEWIS, B. A. Methods for dietary fiber, neutral detergent fiber, and nonstrach polysaccharides in relation to animal nutrition. Journal of Dairy Science, Champaign, v. 74, n. 12, p. 3583-3597, 1991.

SOUSA, B. M. Degradabilidade "in situ" dos componentes nutricionais das silagens de três genótipos de sorgo (CMSXS 180, CMSXS 227 e BR 700). 2001. 73 f. Dissertação (Mestrado em Zootecnia, Produção Animal) - Escola de Veterinária, Belo Horizonte, 2001.

ZAGO, C. P. Cultura de sorgo para produção de silagem de alto valor nutritivo. In: SIMPÓSIO SOBRE NUTRIÇÃO DE BOVINOS, 4., 1991, Piracicaba. Anais... Piracicaba: FEALQ, 1991, p. 169-218. 